\title{
Staurosporine alleviates cisplatin chemoresistance in human cancer cell models by suppressing the induction of SQSTM1/p62
}

\author{
KHALDOON ALSAMMAN ${ }^{1}$ and OMAR S. EL-MASRY ${ }^{1,2}$ \\ ${ }^{1}$ Department of Clinical Laboratory Sciences, College of Applied Medical Sciences, \\ Imam Abdulrahman Bin Faisal University, Dammam 31441, Kingdom of Saudi Arabia; \\ ${ }^{2}$ Department of Applied Medical Chemistry, Medical Research Institute, \\ University of Alexandria, Alexandria 21561, Egypt
}

Received March 22, 2018; Accepted July 17, 2018

DOI: 10.3892/or.2018.6615

\begin{abstract}
Cancer is one of the leading causes of mortality worldwide. Platinum-based chemotherapeutic agents such as cisplatin are the first line of treatment for many types of cancers. However, the development of cisplatin resistance after prolonged treatment is a common cause of cancer recurrence. In the present study, we investigated an approach designed to overcome resistance to cisplatin involving co-treatment with a second chemotherapeutic agent, staurosporine, and examined the role of sequestosome 1 (SQSTM1/p62) in enhancing cellular sensitivity to cisplatin. We utilized experimental models of three different cancers comprising cell lines derived from colon, breast, and ovarian tumors and investigated cell proliferation, morphology and p62 levels after treatment with cisplatin, staurosporine, or a combination of the two. Western blot analysis showed that cisplatin treatment resulted in elevation of p62 levels when compared to the corresponding control cells. Conversely, treatment with staurosporine resulted in a marked reduction in p62 levels in all three cell types and abrogated the cisplatin-induced upregulation of p62. These results suggest that staurosporine could sensitize cancer cells to cisplatin via a mechanism involving downregulation of $\mathrm{p} 62$.
\end{abstract}

\section{Introduction}

Ovarian, breast and colorectal cancers are highly prevalent worldwide, representing a leading cause of human mortality.

Correspondence to: Dr Omar S. El-Masry, Department of Clinical Laboratory Sciences, College of Applied Medical Sciences, Imam Abdulrahman Bin Faisal University, Dammam 31441, Kingdom of Saudi Arabia

E-mail: oselmasry@iau.edu.sa

Key words: cisplatin, breast cancer, colon cancer, ovarian cancer, p62, SQSTM1, staurosporine
Breast cancer is the most commonly diagnosed cancer in women (1), whereas ovarian cancer ranks third among reproductive cancers in women and accounts for $4 \%$ of all malignancies (2). Colorectal cancer was recently reported as the third most common human cancer and ranked fourth in the list of cancers leading to patient mortality (3).

Platinum-containing antineoplastic drugs are used to treat a wide variety of cancers. Cisplatin, the most commonly prescribed platinum-based drug, is the first line of adjuvant or neoadjuvant treatment of ovarian cancer (4), and has shown promise in an animal model of breast cancer (5). Triple-negative breast cancer cell lines, and ovarian and breast tumors lacking BRCA1 are sensitive to cisplatin (6), and a recent clinical trial is currently assessing the effectiveness of the therapeutic use of cisplatin in breast cancer patients (NCT03012477). The broad efficacy of cisplatin is also extended to colon cancer models (7).

Despite its effectiveness in cancer chemotherapy, the development of resistance to cisplatin has been well reported and is associated with cancer recurrence (4). This resistance is mediated, at least in part, by sequestosome 1 (SQSTM1/p62), which upregulates the Keap1/Nrf-2-antioxidant response element (ARE) signaling cascade and promotes cell survival (8). Improved knowledge of such mechanisms has facilitated further research into combination therapies designed to prevent the development of resistance to cisplatin.

Staurosporine is another broad-spectrum antitumor agent that has shown effectiveness in in vitro models of breast (9), ovarian (6) and colon cancer (10). Although the mode of action of staurosporine is poorly understood, and may involve multiple mechanisms (11), the generation of reactive oxygen species (ROS) has been suggested as a mediator of staurosporine-induced apoptosis (12). We therefore postulated that staurosporine, by its presumed multiple modes of action, may provide additive anticancer effects when co-administered with other chemotherapeutic agents. Hence, we sought to investigate the efficacy of the combination of staurosporine and cisplatin using cell culture models of breast, ovarian, and colon cancers, and to gain insights into the possible action mechanisms involving SQSTM1/p62. 


\section{Materials and methods}

Materials and methods. The HCT-116 colon cancer cell line and the MCF-7 breast cancer cell line were obtained from the Medical Technology Center of the Medical Research Institute, University of Alexandria, Egypt. Ovarian cancer cell lines (OVCAR3 and OVCAR4) were purchased form the European Collection of Authenticated Cell Cultures (ECACC; Porton Down, Salisbury, UK). Cisplatin was purchased from MOLEQULE-ON (Auckland, New Zealand). Staurosporine was obtained from Invitrogen/Thermo Fisher Scientific, Inc. (Waltham, MA, USA). Dulbecco's modified Eagle's medium (DMEM) and Roswell Park Memorial Institute (RPMI)-1640 media were purchased from HyClone Laboratories, Inc./GE Healthcare Life Sciences (Logan, UT, USA). Trypsin-EDTA, phosphate-buffered saline (PBS), and fetal bovine serum (FBS) were purchased from Gibco BRL; Thermo Fisher Scientific, Inc. The CCK-8 cell proliferation assessment reagent was obtained from MOLEQULE-ON. Protein standards, associated detection reagents, Laemmli sample buffer, precast gels, Clarity Western ECL Substrate kit, and Trans-Blot Turbo PVDF Transfer Pack and the ChemiDoc MP Imaging System were all purchased from Bio-Rad Laboratories (Hercules, CA, USA). Mouse monoclonal antibody to glyceraldehyde-3-phosphate dehydrogenase (GAPDH; cat. no. ab9484) and rabbit monoclonal antibody to SQSTM1/p62 (cat. no. ab109012) were purchased from Abcam (Cambridge, UK). Horseradish peroxidase (HRP)-conjugated goat anti-mouse $\operatorname{IgG}(\mathrm{H}+\mathrm{L}$; cat. no. 170-6516) and goat anti-rabbit IgG (cat. no. 170-5046) were obtained from Bio-Rad Laboratories.

Cell culture and maintenance. HCT-116, MCF-7, OVCAR3 and OVCAR4 cells were grown as adherent monolayers and incubated at $37^{\circ} \mathrm{C}$ under a humidified atmosphere containing $5 \% \mathrm{CO}_{2}$. HCT-116 and MCF-7 cells were maintained in DMEM (10\% FBS), while RPMI-1640 medium (10\% FBS) was used to culture OVCAR3 and OVCAR4 cells.

Cell proliferation. Cells were trypsinized, counted and seeded in 96-well tissue culture plates at a density of $1 \times 10^{4}$ cells/well. The seeded cells were incubated under standard culture conditions overnight. The next day, media were removed from the wells and fresh media were added onto the double negative wells and the control cells (designated $100 \%$ cell proliferation). Serial dilutions of cisplatin and staurosporine were prepared from stock solutions prepared in dimethyl sulfoxide (DMSO) in DMEM or RPMI-1640 as appropriate. Cells were then treated with cisplatin or staurosporine $(1-100 \mu \mathrm{g} / \mathrm{ml})$ or cisplatin + staurosporine $(100 \mu \mathrm{g} / \mathrm{ml})$. Plates were incubated for $72 \mathrm{~h}$ at $37^{\circ} \mathrm{C}$ under $5 \% \mathrm{CO}_{2}$ before assessment of proliferation.

Cell proliferation was assessed using the CCK-8 kit by incubating control and treated cells with $10 \mu \mathrm{l}$ of CCK-8 reagent for $1 \mathrm{~h}$ and reading the absorbance at $490 \mathrm{~nm}$ using a multi-plate reader. Cell proliferation was then calculated as a percentage of the control cell proliferation by subtracting the mean absorbance of the blank wells from all values, dividing the absorbance values of the treated cells by the mean value of the control cells, and multiplying by 100 . Results are presented as concentration-response relationships.
Cell morphology analysis. Cells were trypsinized, counted, and seeded at a density of $2 \times 10^{5}$ cells/well in 6-well tissue culture plates. Plated cells were then incubated overnight at $37^{\circ} \mathrm{C}$ under $5 \% \mathrm{CO}_{2}$. The next day, cells were incubated with fresh medium containing staurosporine $(100 \mu \mathrm{g} / \mathrm{ml})$, cisplatin $(100 \mu \mathrm{g} / \mathrm{ml})$, or cisplatin + staurosporine for $24 \mathrm{~h}$. Photomicrographs using IRMECO IM-5000 trinocular inverted biological microscope (IRMECO GmBH \& Co. KG, Geesthacht, Germany) linked to ToupView software (ToupTek Photonics, Hangzhou, China) from different microscopic fields were captured to assess the effect of cell treatment on cell morphology. Plates were then re-incubated under the same conditions for another $24 \mathrm{~h}$, and photomicrographs were captured again from different microscopic fields to assess the impact of prolonged incubation with the drugs on morphology in comparison to the corresponding control cells.

Western blotting. HCT-116, MCF-7, OVCAR3 and OVCAR4 cells were trypsinized and counted, and $1 \times 10^{6}$ cells were plated in 9-cm, round tissue culture dishes and allowed to adhere overnight at $37^{\circ} \mathrm{C}$ under $5 \% \mathrm{CO}_{2}$. The next day, the cells were incubated for $24 \mathrm{~h}$ with medium (control), cisplatin $(100 \mu \mathrm{g} / \mathrm{ml})$, staurosporine $(100 \mu \mathrm{g} / \mathrm{ml})$, or cisplatin + staurosporine (100 $\mu \mathrm{g} / \mathrm{ml}$ each). Control and treated cells were washed with ice-cold PBS, scraped, and incubated in $100 \mu \mathrm{l}$ of ice-cold lysis buffer containing protease inhibitor cocktail. Lysates were spun for $10 \mathrm{~min}$ at the maximum speed $(13,400 \mathrm{rpm})$ in a cooling centrifuge and the protein concentration was estimated in the supernatant using the $\mathrm{ABC}$ protein estimation kit. Then, $10 \mu \mathrm{g}$ of protein was loaded into each well of precast gels, electrophoresed and transferred to polyvinylidene difluoride (PVDF) membranes. Membranes were blocked with 5\% skim milk in PBS-Tween (PBST) buffer and probed with an anti-p62 antibody (Abcam). Anti-GAPDH was used for normalization and to ensure equal protein loading. Membranes were washed three times in PBST, incubated with the appropriate secondary antibody, washed again, and the signal was detected using the Bio-Rad ECL detection kit. Antibody dilutions were performed according to the instructions in the datasheet.

Statistical analysis. Data analysis was performed using GraphPad Prism version 7 (GraphPad Software, Inc., La Jolla, CA, USA). Multivariate statistical comparisons were performed using one-way analysis of variance (ANOVA). Multiple comparisons were conducted between the control group and all other groups, and Dunnett's post hoc test was employed whenever the P-value was statistically significant (Dunnett's post hoc test is recommended when comparing multiple groups to a control group). $\mathrm{P} \leq 0.05$ was considered statistically significant.

\section{Results}

Chemoresistance of breast, colon, and ovarian cancer cell lines was reversed in the presence of staurosporine. Cisplatin alone failed to significantly inhibit cell proliferation in comparison to the corresponding negative control following $72 \mathrm{~h}$ of incubation at concentrations up to $100 \mu \mathrm{g} / \mathrm{ml}$. OVCAR3 was the only cell line that showed a partial response to the 
A
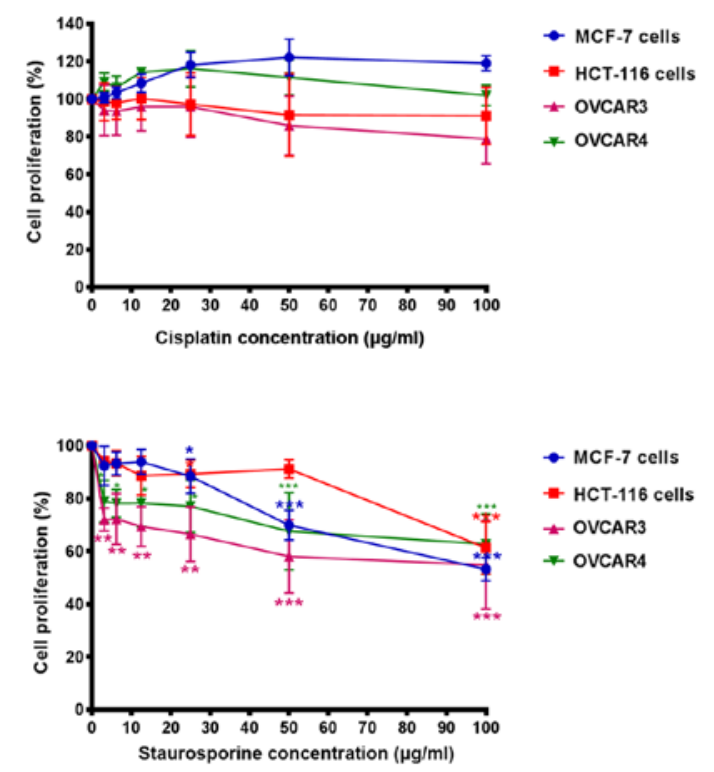

C

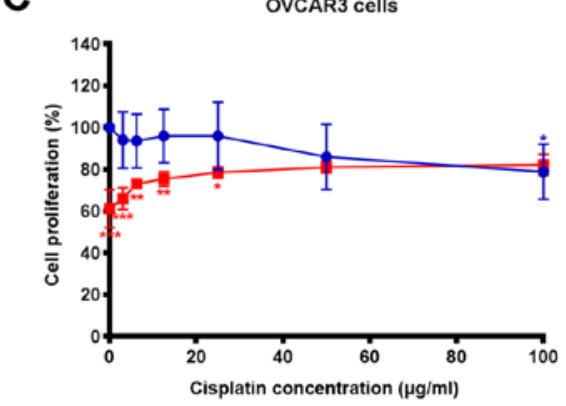

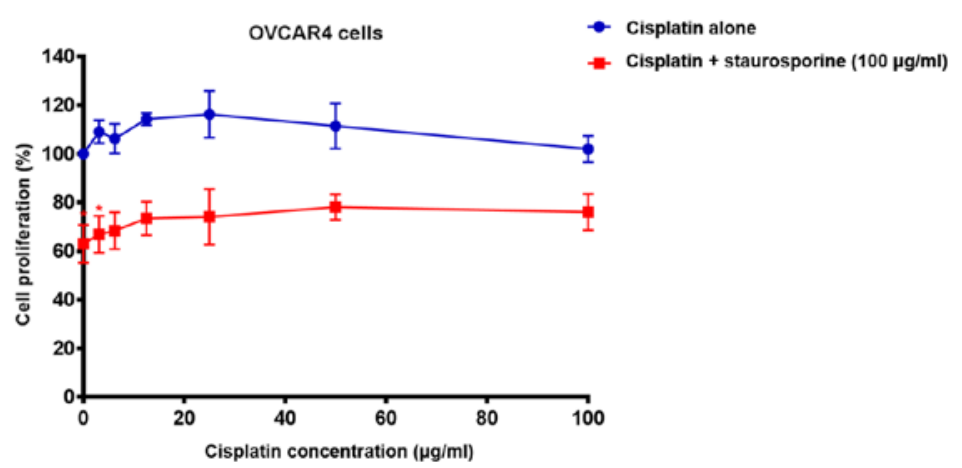

- Cisplatin alone

- Cisplatin + staurosporine (100 $\mu \mathrm{g} / \mathrm{ml})$

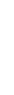

B

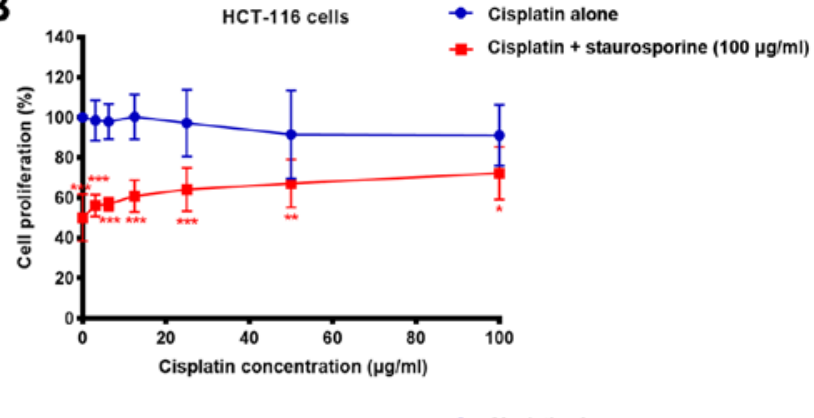

- MCF-7 cells

- HCT-116 cells

+ OVCAR3

* ovcar 4

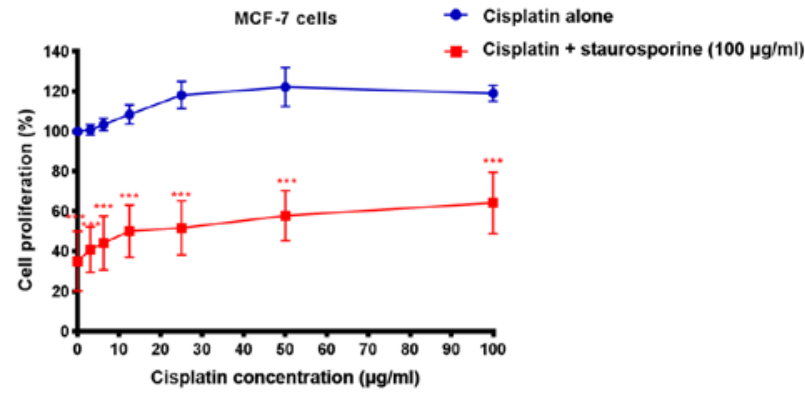


A
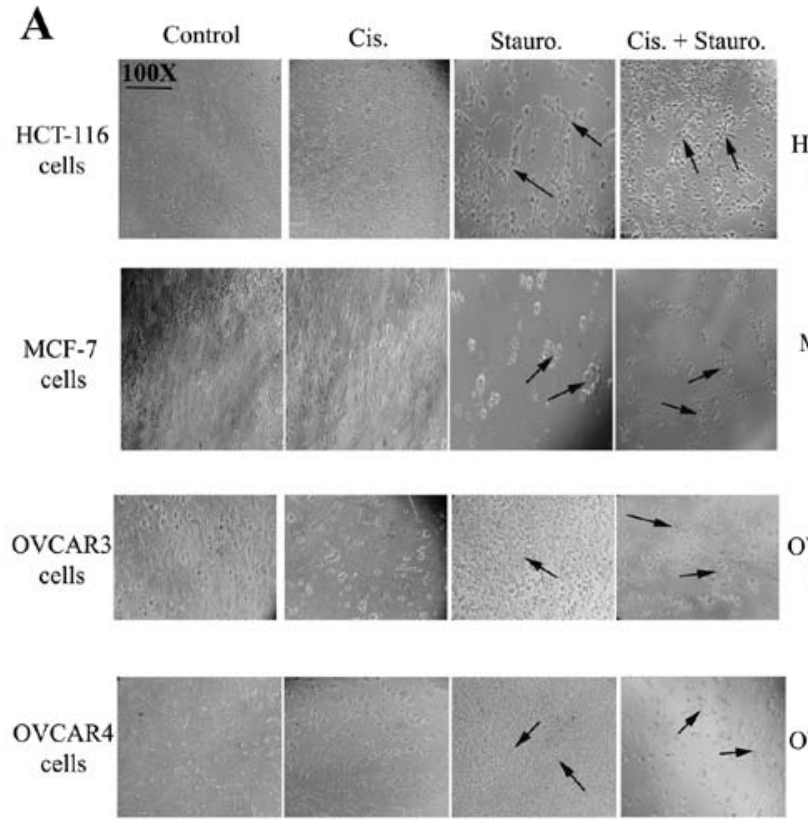

B

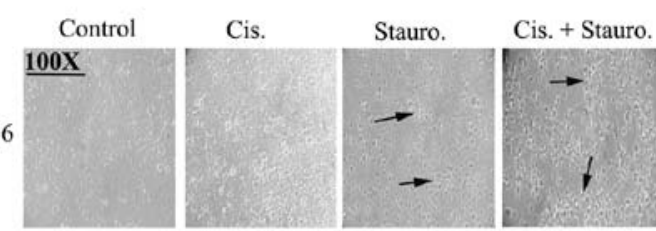

MCF-7 cells

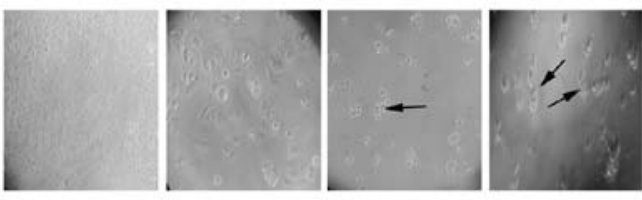

OVCAR3 cells

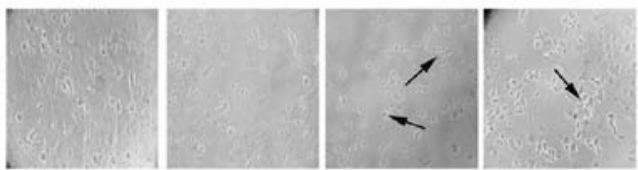

OVCAR4
cells
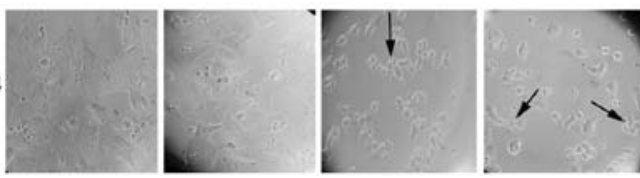

Figure 2. Effects of cisplatin, staurosporine, or a combination of the two on cell morphology of HCT-116, MCF-7, OVCAR3, and OVCAR4 cell lines after incubation for (A) $24 \mathrm{~h}$ and (B) $48 \mathrm{~h}$. Images are representative phase contrast photomicrographs from three independent experiments. Arrows indicate cells with morphological features characteristic of changes occurring during apoptosis. Cis., cisplatin (100 $\mu \mathrm{g} / \mathrm{ml})$; Stauro., staurosporine (100 $\mu \mathrm{g} / \mathrm{ml})$.
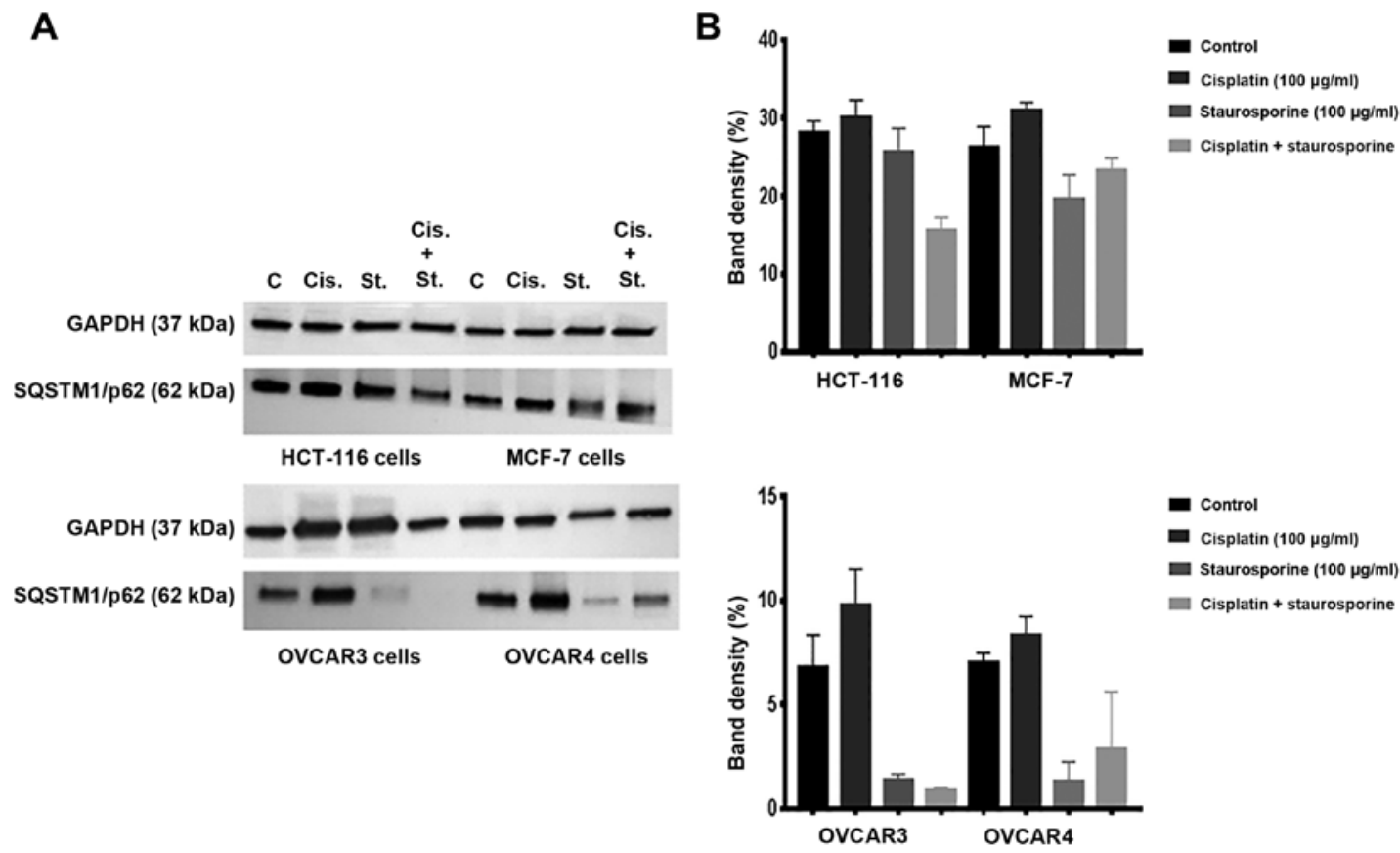

Figure 3. Cisplatin and staurosporine elicit contrasting effects on p62 levels, and staurosporine inhibits cisplatin-induced p62 upregulation. Cells were exposed to cisplatin, staurosporine, or a combination of the two before determination of p62 levels by western blotting. The cell lines used are indicated below the images. GAPDH was used as the loading control. Images are representative blots (A) from two independent experiments and band densitometry (B) is also presented. C, control; Cis., cisplatin; St., staurosporine.

A marked restoration of chemoresistance was observed only in the case of OVCAR3 cells at the highest concentration of cisplatin + staurosporine, where there was no significant difference between the proliferation rate of cells treated with both drugs and the negative control (100\% cell proliferation), and the pattern of cisplatin effect alone was restored (Fig. 1C, top graph).
Microscopic analysis confirms cisplatin chemoresistance and staurosporine-induced sensitization to cisplatin. The photomicrographs presented in Fig. 2 show the effects of cisplatin, staurosporine, or a combination of the two on cell morphology and viability. Control treatments (incubation with DMEM or RPMI-1640) appeared to increase cell density after $48 \mathrm{~h}$ of incubation, with cells exhibiting normal morphology. Cells 
incubated with cisplatin for $24 \mathrm{~h}$ (Fig. 2A) or $48 \mathrm{~h}$ (Fig. 2B) showed normal morphology with no evidence of apoptosis. Incubation of all cell lines with staurosporine for 24 or $48 \mathrm{~h}$ resulted in altered morphology (black arrows) indicative of a marked loss of normal cell structure and reduced cell density, with increasing morphological evidence of cell death. Incubation of cells with both drugs $(100 \mu \mathrm{g} / \mathrm{ml}$ of each drug) resulted in the loss of cell morphology and a concomitant reduction in viable cells, suggesting additive effects or that staurosporine co-treatment resulted in the sensitization of cells to cisplatin.

Western blotting reveals the contrasting effects of cisplatin and staurosporine on p62 levels. Fig. 3A (western blots) and B (band densitometry charts) show the level of p62 protein in HCT-116, MCF-7, OVCAR3 and OVCAR4 cells cultured under control conditions or incubated with cisplatin, staurosporine, or a combination of the two for $24 \mathrm{~h}$. Whereas cisplatin exposure resulted in an increase in the level of p62 in all cell types compared to the corresponding control cells, staurosporine treatment caused an apparent decrease in p62 levels. Co-administration of staurosporine with cisplatin abrogated the cisplatin-mediated increase in p62 levels in all cell lines when compared to either the corresponding control cells or those treated with cisplatin alone, although these data were not statistically significant as the results are representative of 2 replicates of independent experiments. Therefore, statistical comparisons were not possible for this part. GAPDH levels remained consistent, indicating equal protein loading.

\section{Discussion}

The anticancer drugs staurosporine and cisplatin have been extensively studied to investigate their antitumor potential. The mechanism of action of both drugs is believed to involve production of reactive oxygen species (ROS) (13-16). Although cancers do respond to staurosporine in most cases, resistance develops in models where cisplatin is used. In the present study, we investigated the potential of single or combined administration of both drugs to inhibit cellular proliferation in different human cancer cell line models (ovarian, colon, and breast) in an attempt to understand the paradoxical responses observed despite the possibility that a similar mode of action underlies the therapeutic effect of both drugs.

Obvious resistance was observed in all cell lines tested when treated with increasing doses of cisplatin. Resistance to cisplatin was reported in colon cancer in a recent study (17), which reported upregulation of the PI3K pathway and increased levels of X-linked inhibitor of apoptosis (XIAP) as a mediator of this resistance. Similarly, cisplatin resistance was also recently reported in breast cancer (18), and multiple studies have reported the occurrence of cisplatin resistance in ovarian cancer (19-21). Increasing concentrations of staurosporine, in contrast, reduced the proliferation of all cell types tested. These results were confirmed by microscopy, which revealed a loss of normal cell morphology and confirmed the ability of both drugs in combination to inhibit cell proliferation. These observations are in concordance with the reported efficacy of staurosporine in inhibiting the growth of breast cancer cells (9). The antitumor potential of staurosporine in
HT-29 colon cancer cells has also been reported, with high, but not low, concentrations of the drug associated with higher expression of carcinoembryonic antigen (CEA). In contrast, low concentrations were associated with lower expression of CEA in C22.20 cells (a sub-line of HT-29), suggesting that staurosporine could be a potent antitumor agent as well as a sensitizer for biomarkers that may aid in diagnosis $(22,23)$. However, a marked regain of resistance was observed in OVCAR3 cells that were co-treated with cisplatin and staurosporine. This pattern of response should draw attention to the importance of further investigation of the impact of cellular characteristics on application of the current hypothesis of using staurosporine (in our case), or other drugs to sensitize cancer cells to platinum-based chemotherapy when chemoresistance is a clinical concern. For example, deciding on drug dose could be an important factor that may have a major influence on sensitization of cells without possible regain of resistance.

The reported antitumor effects of staurosporine are thought to involve the modulation of cell cycle progression and the induction of anti-survival pathways, as reviewed previously (23). Sequestosome 1 (p62), a protein that participates in a survival pathway involving Keap1 and Nrf2, is thought to contribute to cisplatin resistance by allowing translocation of Nrf2 to the nucleus, thereby upregulating antioxidant gene expression in addition to other reported mechanisms $(8,24)$. In this context, because ROS generation has been proposed as a central mediator of the anticancer effects of cisplatin and the Keap1/Nrf2 system is considered to be one possible inducer of cisplatin resistance in cancer cells (25), staurosporine could contribute to a reduction in cisplatin resistance in cancer cells.

In the present study, cisplatin treatment resulted in elevation of p62 levels compared to control cells, whereas staurosporine treatment resulted in an obvious reduction of p62 levels in all three cell types, thereby potentiating the effects of cisplatin. These results suggest that staurosporine could sensitize cancer cells to cisplatin via a mechanism involving the downregulation of p62. It is possible that co-administration of both drugs may reduce cell proliferation and overcome cisplatin resistance in other cancer models.

It is of note to mention that despite reporting p62 as a potential target by which staurosporine could sensitize different types of human cancer cells to cisplatin, this hypothesis should be further investigated and verified in a more comprehensive research model. For example, the role of p62 as a pivotal mediator of cisplatin chemoresistance should be investigated along with the signaling pathways where it functions; the Keap/Nrf/ROS axis, for instance. The influence of upregulation and downregulation of p62 in these types of human cancer cells could be thoroughly investigated by employing gene expression analysis to spot other biomarkers that could be crucial mediators of chemoresistance either independently or by working side-by-side with p62. In addition, experimental models could be used to investigate the potential correlation between p62 upregulation and downregulation and major cell survival pathways for better understanding of the involvement of p62 in the regulation of cell survival and proliferation where staurosporine and cisplatin are used, or, perhaps, other treatment regimens. In this respect, this avenue of research warrants further investigation. 


\section{Acknowledgements}

Not applicable.

\section{Funding}

No funding was received.

\section{Availability of data and materials}

The datasets used during the present study are available from the corresponding author upon reasonable request.

\section{Authors' contributions}

KA analyzed the data, carried out western blotting experiments and contributed to manuscript writing. OSEM designed the study, carried out cell proliferation experiments and photomicrography and contributed to the manuscript writing. Both authors read and approved the manuscript and agree to be accountable for all aspects of the research in ensuring that the accuracy or integrity of any part of the work are appropriately investigated and resolved.

\section{Ethics approval and consent to participate}

Not applicable.

\section{Patient consent for publication}

Not applicable.

\section{Competing interests}

The authors state that they have no competing interests.

\section{References}

1. Ghoncheh M, Pournamdar Z and Salehiniya H: Incidence and mortality and epidemiology of breast cancer in the world. Asian Pac J Cancer Prev 17: 43-46, 2016.

2. Ferlay J, Shin HR, Bray F, Forman D, Mathers C and Parkin DM: Estimates of worldwide burden of cancer in 2008: GLOBOCAN 2008. Int J Cancer 127: 2893-2917, 2010.

3. Arnold M, Sierra MS, Laversanne M, Soerjomataram I, Jemal A and Bray F: Global patterns and trends in colorectal cancer incidence and mortality. Gut 66: 683-691, 2017.

4. Ai Z, Lu Y, Qiu S and Fan Z: Overcoming cisplatin resistance of ovarian cancer cells by targeting HIF-1-regulated cancer metabolism. Cancer Lett 373: 36-44, 2016.

5. Chen Y, Han F, Cao LH, Li C, Wang JW, Li Q, Zheng W, Guo ZX, Li AH and Zhou JH: Dose-response relationship in cisplatin-treated breast cancer xenografts monitored with dynamic contrast-enhanced ultrasound. BMC Cancer 15: 136 , 2015.

6. Wahba HA and El-Hadaad HA: Current approaches in treatment of triple-negative breast cancer. Cancer Biol Med 12: 106-116, 2015.
7. Son DJ, Hong JE, Ban JO, Park JH, Lee HL, Gu SM, Hwang JY, Jung MH, Lee DW, Han SB and Hong JT: Synergistic inhibitory effects of cetuximab and cisplatin on human colon cancer cell growth via inhibition of the ERK-dependent EGF receptor signaling pathway. Biomed Res Int 2015: 397563, 2015.

8. Xia M, Yu H, Gu S, Xu Y, Su J, Li H, Kang J and Cui M: p62/SQSTM1 is involved in cisplatin resistance in human ovarian cancer cells via the Keap1-Nrf2-ARE system. Int J Oncol 45: 2341-2348, 2014.

9. Xue LY, Chiu SM and Oleinick NL: Staurosporine-induced death of MCF-7 human breast cancer cells: A distinction between caspase-3-dependent steps of apoptosis and the critical lethal lesions. Exp Cell Res 283: 135-145, 2003.

10. del Solar V, Lizardo DY, Li N, Hurst JJ, Brais CJ and Atilla-Gokcumen GE: Differential regulation of specific sphingolipids in colon cancer cells during staurosporine-induced apoptosis. Chem Biol 22: 1662-1670, 2015.

11. Manns J, Daubrawa M, Driessen S, Paasch F, Hoffmann N, Löffler A, Lauber K, Dieterle A, Alers S, Iftner T, et al: Triggering of a novel intrinsic apoptosis pathway by the kinase inhibitor staurosporine: Activation of caspase-9 in the absence of Apaf-1. FASEB J 25: 3250-3261, 2011.

12. Olguin-Albuerne M, Dominguez G and Morén J: Effect of staurosporine in the morphology and viability of cerebellar astrocytes: Role of reactive oxygen species and NADPH oxidase. Oxid Med Cell Longev 2014: 678371, 2014.

13. Marullo R, Werner E, Degtyareva N, Moore B, Altavilla G, Ramalingam SS and Doetsch PW: Cisplatin induces a mitochondrial-ROS response that contributes to cytotoxicity depending on mitochondrial redox status and bioenergetic functions. PLoS One 8: e81162, 2013.

14. Zhaleh H, Azadbakht $M$ and Bidmeshki Pour A: Possible involvement of calcium channels and plasma membrane receptors on Staurosporine-induced neurite outgrowth. Bosn J Basic Med Sci 12: 20-25, 2012.

15. Zhang XD, Gillespie SK and Hersey P: Staurosporine induces apoptosis of melanoma by both caspase-dependent and -independent apoptotic pathways. Mol Cancer Ther 3: 187-197, 2004.

16. Gil J, Almeida S, Oliveira CR and Rego AC: Cytosolic and mitochondrial ROS in staurosporine-induced retinal cell apoptosis. Free Radic Biol Med 35: 1500-1514, 2003.

17. Xiong Z, Fu Z, Shi J, Jiang X and Wan H: HtrA1 down-regulation induces cisplatin resistance in colon cancer by increasing XIAP and activating PI3K/Akt pathway. Ann Clin Lab Sci 47: 264-270, 2017.

18. Cataldo A, Cheung DG, Balsari A, Tagliabue E, Coppola V, Iorio MV, Palmieri D and Croce CM: miR-302b enhances breast cancer cell sensitivity to cisplatin by regulating E2F1 and the cellular DNA damage response. Oncotarget 7: 786-797, 2016.

19. Chen J, Solomides C, Parekh H, Simpkins F and Simpkins H: Cisplatin resistance in human cervical, ovarian and lung cancer cells. Cancer Chemother Pharmacol 75: 1217-1227, 2015.

20. Eckstein N: Platinum resistance in breast and ovarian cancer cell lines. J Exp Clin Cancer Res 30: 91, 2011

21. Wang $\mathbf{J}$ and $\mathrm{Wu}$ GS: Role of autophagy in cisplatin resistance in ovarian cancer cells. J Biol Chem 289: 17163-17173, 2014.

22. Aquino A, Prete SP, Baier S, Cappelletti D, Greiner JW, De Vecchis L, Graziani G and Bonmassar E: Staurosporine increases carcinoembryonic antigen expression in a human colon cancer cell line. J Chemother 12: 167-172, 2000.

23. Aquino A, Prete SP, Balduzzi A, Formica V, Fossile E, Bonmassar L, Concolino F, Bonmassar E and Graziani G: Treatment of peripheral blood with staurosporine increases detection of circulating carcinoembryonic antigen positive tumor cells. Int J Cancer 100: 119-121, 2002

24. Yan XY, Zhang Y, Zhang JJ, Zhang LC, Liu YN, Wu Y, Xue YN, Lu SY, Su J and Sun LK: p62/SQSTM1 as an oncotarget mediates cisplatin resistance through activating RIP1-NF- $\kappa \mathrm{B}$ pathway in human ovarian cancer cells. Cancer Sci 108: 1405-1413, 2017.

25. Brozovic A, Ambriovic-Ristov A and Osmak M: The relationship between cisplatin-induced reactive oxygen species, glutathione, and BCL-2 and resistance to cisplatin. Crit Rev Toxicol 40: 347-359, 2010. 